\title{
ARTIGO CIENTÍFICO \\ Produtividade de Brassica oleracea em sistema de transição orgânica no Sul do Brasil
}

\section{Productivity of Brassica oleracea in an organic transition system in the South of Brazil}

\author{
Cláudia Solange de Moura ${ }^{1}$, Ramiro Pereira Bisognin ${ }^{2}$, Danni Maisa da Silva ${ }^{3}$, Divanilde Guerra ${ }^{4}$, Renan Bianchetto , \\ Eduardo Lorensi de Souza ${ }^{6 *}$
}

\begin{abstract}
Resumo: A produção sustentável de alimentos é um paradigma atual da agricultura moderna. Diante da redução dos estoques mundiais de fertilizantes tradicionalmente empregados na agricultura, fontes alternativas de adubação podem ser utilizadas como opção de substituição parcial de nutrientes em sistemas de transição. O presente trabalho teve como objetivo avaliar a influência de fontes de nutrientes no cultivo da couve manteiga crioula em transição orgânica. Nesse estudo foram utilizadas quatro fontes de fertilização do solo, formando quatro tratamentos: fertilizante mineral NPK, adubo orgânico cama de frango, calcário e pó de rocha. O experimento foi conduzido em uma propriedade no município de Três Passos, Rio Grande do Sul. O delineamento experimental foi em blocos ao acaso com quatro repetições. Foram avaliadas: altura de plantas, número de folhas de plantas, peso de folhas, peso de plantas e produtividade. O fertilizante orgânico cama de frango obteve valor próximo ao adubo mineral NPK quanto à altura, peso, número de folhas e produtividade. Verificou-se que os tratamentos com calcário, pó de rocha, cama de frango e NPK obtiveram valores médios, respectivamente, de 7,11, 15 e $23 \mathrm{Mg} \mathrm{ha}^{-1}$ de produtividade. O tratamento com pó de rocha apresentou resultado similar em relação à cama de frango em todos os parâmetros avaliados. Com a utilização do pó de rocha como fonte de adubação é possível obter produtividades estatisticamente semelhantes àquelas obtidas quando a cama de frango é utilizada na couve, evidenciando o uso do pó de rocha como fonte alternativa para a fertilização.
\end{abstract}

Palavras-chave: Produção orgânica; Alimentação saudável; Hortaliças; Brassica oleracea.

Abstract: Sustainable food production is a current paradigm of modern agriculture. Faced with the reduction of virtual stocks of traditionally agricultural fertilizer, alternative sources of fertilization can be used of systems. The present work had a significant influence on the sources of nutrients, the cultivation of butter kale, the butter prepared in organic transition. In this work four soil fertilization sources were used, forming four treatments: NPK mineral fertilizer, organic fertilizer chicken manure, limestone and rock dust. The experiment was conducted in a property in the municipality of Três Passos, Rio Grande do Sul. The experimental design was in randomized blocks with four replicates. The following were evaluated: plant height, number of plant leaves, leaf weight, plant weight and yield. The chicken manure fertilizer obtained value close to NPK mineral fertilizer regarding height, weight, number of leaves and productivity. It was verified that the treatments with limestone, rock dust, organic fertilizer chicken manure and NPK had average values, respectively, of 7, 11, 15 and $23 \mathrm{Mg} \mathrm{ha}{ }^{-1}$ of productivity. The treatment with rock dust had a similar result in relation to the organic fertilizer chicken manure in all evaluated parameters. With the use of rock dust as a source of fertilization it is possible to obtain statistically similar results when the organic fertilizer chicken manure is used in feeding, evidencing the use of rock dust as an alternative source for fertilization.

Key words: Organic production; Healthy eating; Vegetables; Brassica oleracea.

\footnotetext{
*Autor para correspondência

Recebido para publicação em 06/12/2017; aprovado em 09/03/2018

${ }^{1}$ Especialista em Segurança Alimentar e Agroecologia, Universidade Estadual do Rio Grande do Sul, Três Passos, Rio Grande do Sul. claudiasolangedemoura@gmail.com

${ }^{2}$ Mestre em Tecnologia Ambiental, Professor Assistente, Universidade Estadual do Rio Grande do Sul, Três Passos, Rio Grande do Sul. ramirobisognin@uergs.edu.br

${ }^{3}$ Doutora em Ciência do Solo, Professora Adjunta, Universidade Estadual do Rio Grande do Sul Três Passos, Rio Grande do Sul. danni-silva@uergs.edu.br

${ }^{4}$ Doutora em Fitotecnia, Professora Adjunta, Universidade Estadual do Rio Grande do Sul Três Passos, Rio Grande do Sul. divanilde-guerra@uergs.edu.br

${ }^{5}$ Aluno de graduação em Agronomia, Universidade Estadual do Rio Grande do Sul Três Passos, Rio Grande do Sul. renan.bianchetto@ yahoo.com.br

${ }^{3}$ Doutor em Ciência do Solo, Professor Adjunto, Universidade Estadual do Rio Grande do Sul, Três Passos, Rio Grande do Sul. elorensi@yahoo.com.br
} 


\section{INTRODUÇÃO}

Atualmente a produção de alimentos utiliza incessantemente grandes quantidades de pesticidas, inseticidas e adubos químicos (MAZOYER; ROUDART, 2001). De acordo com Saab e Paula (2008), a escassez de reservas minerais como fósforo $(\mathrm{P})$, potássio $(\mathrm{K})$ e outros, denota a importância e a necessidade de adoção de consumo racional e estratégico desses nutrientes para a produção de alimentos e produtos industriais, configurando-se como fatores de segurança econômica para as nações.

Segundo Cella e Rossi (2010), o Brasil consome aproximadamente 25 milhões de toneladas de fertilizantes formulados a base de Nitrogênio ( $\mathrm{N}, \mathrm{P}$ e K), sendo o quarto maior consumidor mundial. Em 2016, o consumo de NPK no Brasil atingiu o patamar de 33,5 milhões de toneladas. Para sustentar essa agricultura o país necessita importar $73 \%$ do N, $92 \%$ do $\mathrm{K}$ e $46 \%$ do $\mathrm{P}$ que é utilizado na agricultura. As reservas mundiais de $\mathrm{K}$, por exemplo, somam 16 bilhões de toneladas, enquanto que as de $\mathrm{P}$ representam 50 bilhões de toneladas (IFA, 2009).

No entanto, esse modelo convencional de produção de alimentos, altamente dependente de adubação química, passa por um campo acelerado de modificações e transições, com expectativas de cuidar e valorizar a forma de usar os recursos naturais e dar importância à continuidade de uma produção de alimentos saudável e com qualidade (CAPORAL; COSTABEBER, 2000; LOPES; LOPES, 2011). Dessa forma, produzir alimentos e ser sustentável é um dos paradigmas atuais da agricultura moderna. A sustentabilidade no processo de produção de alimentos é uma necessidade para a manutenção da qualidade ambiental dos agroecossistemas (GLIESSMAN, 2000).

No Brasil houve um aumento significativo na produção de orgânicos em 2015, com índices de 51,7\% em relação aos anos anteriores (BRASIL, 2015). Assim, a produção de base ecológica praticada principalmente nas pequenas propriedades rurais do País visa colocar a agricultura familiar como peça chave do desenvolvimento da produção de alimentos saudáveis para a população, já que a maior parte dos alimentos produzidos para consumo (70\%) é oriundo da pequena propriedade rural, o que a torna essencial para a produção de alimentos básicos à população brasileira (HAHN et al., 2017).

Nesse contexto, para que a transição orgânica possa ocorrer, são necessários insumos alternativos e tecnologias que promovam uma produção eficiente. Dentre as alternativas existentes e que podem ser utilizadas para a substituição de fertilizantes destaca-se a utilização de pó de rocha e adubação orgânica com cama de frango.

Segundo Malamed e Gaspar (2005), o emprego do modelo de remineralização do solo com o uso de pó de rocha constitui uma alternativa viável em termos econômicos e ecológicos, devido ao baixo custo do processo de beneficiamento que envolve apenas a trituração das rochas usadas na fabricação do produto. Logo, pode-se dizer que a rochagem é uma prática que induz a fertilização do solo, viabilizando o equilíbrio do sistema como um todo (THEODORO, 2000), ou seja, essa técnica promove o rejuvenescimento de solos de baixa fertilidade sem afetar o equilíbrio do meio ambiente (LEONARDOS et al., 1976).

A utilização de pó de rocha possibilita uma série de benefícios, tais como proporcionar macro e micronutrientes não disponíveis em fertilizantes químicos solúveis fornecedores de NPK, baixo custo, aumento da fertilidade do solo em longo prazo e favorecimento das propriedades químicas para elevar o pH do solo. No entanto, deve-se levar em consideração que o pó de rocha possui liberação lenta em alguns solos, como naqueles que apresentam acidez e são empobrecidos de nutrientes (VAN STRAATEN, 2006).

Além disso, a utilização de estercos e outros compostos orgânicos também se apresentam como alternativas promissoras capazes de reduzir a quantidade de fertilizantes químicos aplicados nas culturas agrícolas (ALMEIDA et al., 1982). Segundo Silva et al. (2011), a adubação orgânica não só incrementa a produtividade mas também produz plantas com características qualitativas melhores que as cultivadas com adubos minerais. Experimentos reportam os efeitos do uso da cama de aviário e demonstram algumas vantagens como a alta concentração de macronutrientes (ZHANG et al., 2002).

Dessa forma, o uso de cama de aviário como adubação orgânica permite ao mesmo tempo uma forma adequada de descarte desses resíduos e também uma forma de adubação orgânica capaz de melhorar as características físicas, químicas e biológicas do solo (MCGRATH et al., 2009). A cama de aviário apresenta diversas vantagens em relação ao material in natura, como aumento no carbono total da matéria orgânica do solo (MOS) (ADELI et al., 2008; SINGH et al., 2009), maior capacidade de retenção e infiltração de água do solo (KINGERY et al., 1994), além de aumentar o pH do solo (ZHANG, 1998).

Além dessas, outra alternativa simples de disponibilização da maior parte dos nutrientes essenciais às plantas e que ainda pode potencializar uma maior produtividade é a correção do $\mathrm{pH}$ do solo em áreas que nunca receberam cultura ou calagem. Esse processo é simples e pode ser realizado apenas com a aplicação de calcário, que se constitui em uma maneira benéfica, econômica e viável de corrigir a acidez do solo na camada arável (VALE et al., 1997), o que permite a disponibilização da maioria dos nutrientes exigidos pelas plantas e a redução dos níveis daqueles elementos potencialmente tóxicos para as plantas, como o caso do alumínio (Al). Conforme Raij (2011), nem sempre a prática é adotada, ou então é realizada de modo inadequado, portanto, ineficaz. Segundo o autor, a aplicação do calcário promove a elevação do $\mathrm{pH}$, neutraliza o alumínio tóxico, fornece cálcio e magnésio, propicia maior desenvolvimento do sistema radicular das plantas e melhora a eficiência do uso dos nutrientes e da água presentes no solo (CAIRES et al., 2004).

Diante da necessidade de se buscar alternativas de adubação e correção dos atributos do solo para a produção de alimentos mais saudáveis e de modo sustentável, este estudo teve como objetivo avaliar a influência de fontes de nutrientes no cultivo da couve manteiga crioula em transição orgânica.

\section{MATERIAL E MÉTODOS}

\section{Local, solo, clima e condução da cultura}

Este estudo foi conduzido, em um experimento em condições de campo, com a cultura da couve manteiga crioula (Brassica oleracea spp.). A área experimental localiza-se no município de Três Passos, no Noroeste do Estado do Rio Grande do Sul, sob coordenadas: $27^{\circ} 27^{\prime} 31^{\prime \prime}$ de latitude Sul e $53^{\circ} 55^{\prime} 49^{\prime \prime}$ de longitude Oeste. O solo da área experimental é classificado como Neossolo (SANTOS, 2013). O clima da 
região é classificado como tipo cfa, segundo a classificação de Köeppen, apresentando temperatura média para o mês mais frio entre -3 e $18{ }^{\circ} \mathrm{C}$ e superior a $22^{\circ} \mathrm{C}$ no mês mais quente. Com relação a precipitação, é uniforme durante o ano todo com totais superiores a $1.200 \mathrm{~mm}$.

Anteriormente à instalação do experimento, a área era cultivada com gramíneas perenes para alimentação do gado. $\mathrm{Na}$ área em questão, não eram realizados manejos nas gramíneas para pastagem, ou seja, essas gramíneas eram espontâneas e a área permanecia em pousio para o desenvolvimento das gramíneas até o momento da entrada dos animais para o pastejo. Antes da instalação do experimento, o solo foi revolvido com arado e, após, foi realizada a construção dos canteiros de forma manual com uso de enxada, pá de corte, enxadão e rastelo.

As sementes crioulas para a produção das mudas de couve foram obtidas de produtores de assentamentos do município de Candiota - RS. A semeadura dessas sementes foi realizada em bandejas de isopor com 128 alvéolos, cada, em 01/05/2016, tendo sido introduzida de duas a três sementes por célula com substrato para plantas tecnomax, com $1 \mathrm{~cm}$ de profundidade. Ao término da semeadura cobriuse a semente com substrato comercial para plantas, composto por casca de pinus e eucalipto, fibra de coco, fibra de papel recuperada e vermiculita. Posteriormente, foi realizada a irrigação para manutenção da umidade do substrato, com auxílio de um regador, uma vez ao dia. A emergência das plântulas ocorreu cerca de 15 dias após a semeadura.

O transplante das mudas para os canteiros foi realizado após 35 dias da semeadura nas bandejas, adotando-se o espaçamento entre mudas de $0,30 \mathrm{~m}$ e entre linhas de $0,30 \mathrm{~m}$. O controle de plantas daninhas foi realizado com capina manual.

\section{Delineamento experimental e tratamentos}

O delineamento utilizado foi em blocos ao acaso com quatro repetições de cada tratamento. Cada repetição era formada por canteiros de 2,5 $\mathrm{m}$ de comprimento e $0,65 \mathrm{~m}$ de largura, com três linhas de plantio. Os tratamentos consistiram de uma cultivar crioula de couve manteiga, com diferentes fontes de adubação conforme descrito a seguir: T1: Couve manteiga com aplicação de calcário. T2: Couve manteiga com adubação orgânica a base de cama de frango. T3: Couve manteiga com adubação a base de pó de rocha. T4: Couve manteiga com adubação a base de NPK.

Anterior à aplicação das adubações nos canteiros, foi realizada a amostragem da área para a realização da análise de solo. As características da área eram as seguintes: teor de argila 56\%; pH em $\mathrm{H}_{2} \mathrm{O}$ 5,5; índice SMP 5,9; matéria orgânica 2,8\%; P $\left(\right.$ Melich $\left.^{-1}\right) 5,1 \mathrm{mg} \mathrm{dm}^{-3} ; \mathrm{K}\left(\mathrm{Melich}^{-1}\right) 162$

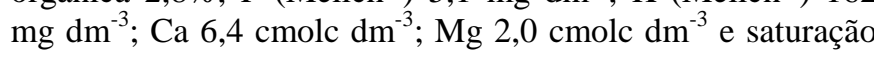
por bases $64,3 \%$.

Após a realização da análise do solo da área experimental, realizou-se a aplicação, em superfície, dos fertilizantes avaliados e do calcário para, após, proceder com o transplante das mudas.

As doses de fertilizantes utilizadas nos tratamentos foram estabelecidas e ajustadas conforme as recomendações do Manual de adubação e calagem para os estados do Rio Grande do Sul e Santa Catarina, que segue as recomendações da Comissão de Química e Fertilidade do Solo (CQFS $\mathrm{RS} / \mathrm{SC}, 2004)$.
Nesse estudo foi avaliada a altura das plantas, número de folhas por planta, peso das folhas, peso das plantas e produtividade.

Para a avaliação da altura de plantas foram colhidas três plantas de cada repetição, num total de 12 plantas avaliadas por tratamento. Após a colheita, foi medida a altura de cada planta com auxílio de uma trena métrica graduada.

Para a avaliação do número de folhas, cada planta teve suas folhas contabilizadas e, após, foi feita uma média para compor o número de folhas em cada repetição, de cada tratamento. Em relação à avaliação do peso de plantas, cada uma das três plantas, de cada repetição, foi pesada individualmente e, ao final, fez-se uma média de peso de três plantas por repetição em cada tratamento testado.

Os resultados obtidos nesse estudo foram submetidos à análise de variância e ao teste de Tukey a 5\% de probabilidade de erro, utilizando-se os procedimentos disponíveis no pacote estatístico Sisvar (FERREIRA, 2011).

\section{RESULTADOS E DISCUSSÃO}

Em relação à altura de plantas, o tratamento com calcário apresentou 40,6 cm de altura, enquanto que os tratamentos pó de rocha, cama de frango e NPK apresentaram alturas superiores, respectivamente, de 49,7; 57,7 e $65 \mathrm{~cm}$ de altura (Figura 1)

Figura 1. Altura de plantas $(\mathrm{cm})$ de couve manteiga produzida em sistema de transição orgânica com diferentes fontes de fertilização no Noroeste do Rio Grande do Sul.

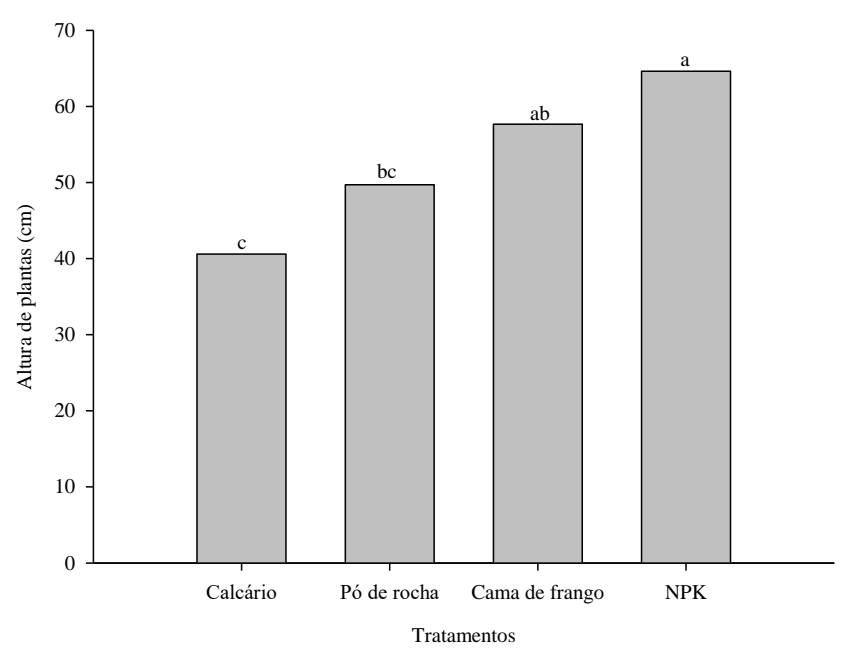

Letras diferentes entre as barras verticais indicam a existência de diferença estatística significativa pelo teste de Tukey com $5 \%$ de probabilidade de erro.

Observando-se a Figura 1, verifica-se que o tratamento com NPK foi o que promoveu a maior altura de plantas, sendo estatisticamente superior aos tratamentos que receberam pó de rocha e calcário. No entanto, o tratamento que recebeu adubação orgânica com cama de frango não diferiu estatisticamente do tratamento com NPK. Por sua vez, o tratamento que recebeu fertilização com pó de rocha foi estatisticamente semelhante ao que recebeu fertilização com cama de frango.

Cabe destacar, ainda com base na Figura 1, que a adubação com NPK e com a cama de frango influenciou positivamente no crescimento da couve. Nesse sentido, Rodrigues et al. (2009) mencionam que a matéria orgânica de origem animal e/ou vegetal exerce, quando fornecida em 
doses adequadas, efeitos positivos sobre o rendimento das culturas devido aos nutrientes nela contidos. Fato que leva ao aumento da disponibilidade de nutrientes na fase solúvel do solo para as plantas (BLUM et al., 2003). De acordo com Branco et al. (2001), é conhecido o fato de que, em presença de matéria orgânica, os fosfatos insolúveis no solo tendem a se tornar disponíveis, provavelmente por atividades microbianas saprofíticas, uma vez que microrganismos decompositores, presentes no adubo orgânico, recorrem a estratégias particulares para liberação de fatores que se tornam limitantes, ou seja, o carbono orgânico presente fornece energia necessária à disponibilização de $\mathrm{P}$ e assim prossegue o ciclo nutricional que de outra forma seria interrompido.

A influência do $\mathrm{N}$ aumenta o número e o tamanho das folhas, bem como massa seca e parte aérea da planta (FERREIRA et al., 2003). O efeito benéfico do $\mathrm{N}$ é amplamente relatado na literatura (NILSON, 1980; BATAL et al., 1997; CAMARGO et al., 2008). Segundo Souza et al. (2005), o emprego de fertilizantes minerais especialmente os nitrogenados, em alface, é uma prática agrícola que traz resultados satisfatórios em termos de produtividade. Já Amparo (2003), destaca que a mineralização do solo é lenta e gradativa, motivo pelo qual não há nutrientes disponíveis na fase inicial, o que justifica os diferentes resultados obtidos especialmente para os tratamentos que receberam pó de rocha e calcário.

Os resultados obtidos no presente trabalho foram próximos aos encontrados no cultivo de alface conduzido no Instituto Federal de Educação Ciência e Tecnologia, Campus de Crato - $\mathrm{CE}$, onde o acréscimo de adubo orgânico e mineral promoveu aumento em todas as variáveis analisadas em relação ao tratamento testemunha. $O$ tratamento que promoveu melhores resultados de produção em termos de número de folhas foi a cama de frango, semelhantes ao obtido com o adubo mineral (PEIXOTO FILHO et al., 2013).

Em relação ao número de folhas, verificou-se que os tratamentos com calcário, pó de rocha, cama de frango e NPK apresentaram, respectivamente, 13, 14, 15 e 18 folhas por planta, não apresentando diferença estatística entre eles (Figura 2).

Figura 2. Número de folhas de plantas de couve manteiga produzida em sistema de transição orgânica com diferentes fontes de fertilização no Noroeste do Rio Grande do Sul.

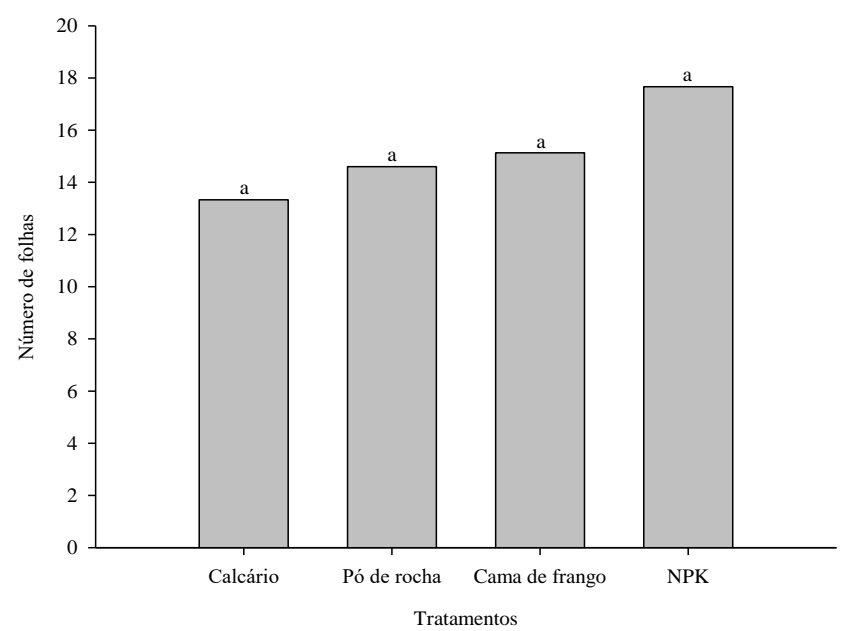

Letras diferentes entre as barras verticais indicam a existência de diferença estatística significativa pelo teste de Tukey com $5 \%$ de probabilidade.
Steiner et al. (2009), avaliando diferentes fontes de fertilizantes, também não observaram diferenças significativas para parâmetros de número de folhas, área foliar, massa fresca de plantas e da parte aérea, para a cultura do almeirão. Avaliações feitas por Nakagawa et al. (1992) no cultivo de alface, concluíram que a utilização de $150 \mathrm{~g}$ de composto orgânico por vaso, com diferentes resíduos agrícolas, não produziram diferenças significativas para biomassa fresca de folhas e caules.

Em outro estudo, utilizando diversas fontes de adubação verde para alface, Fontanétti et al. (2006) não identificaram diferenças significativas para as características agronômicas estudadas, o que indica a viabilidade de adubos verdes em complementação à adubação orgânica, podendo substituir a adubação mineral para produção dessa hortaliça.

Verificou-se que os tratamentos com calcário, pó de rocha, cama de frango e NPK resultaram, respectivamente, em 14, 20, 25 e $35 \mathrm{~g}$ por planta (Figura 3 ).

Figura 3. Peso de folhas (g) de plantas de couve manteiga produzida em sistema de transição orgânica com diferentes fontes de fertilização no Noroeste do Rio Grande do Sul.

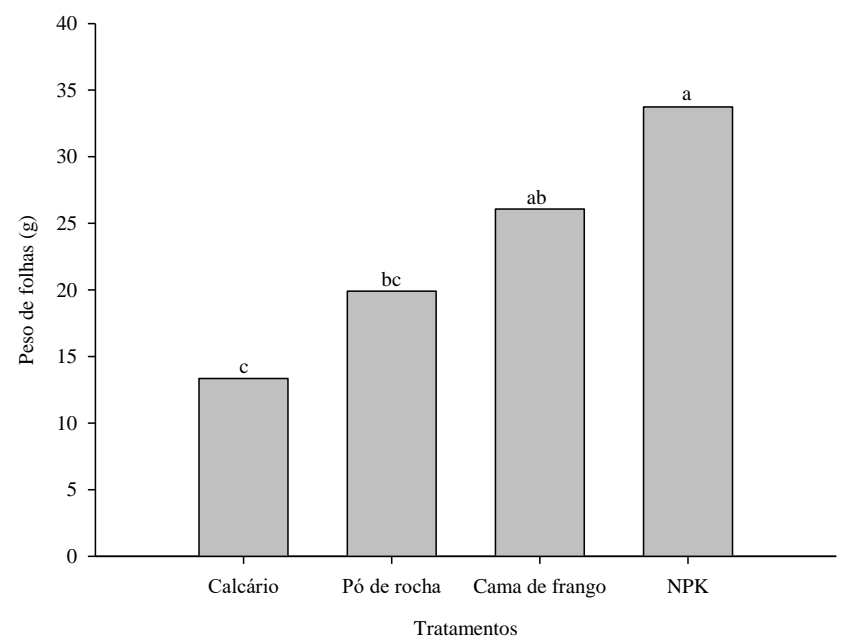

Letras diferentes entre as barras verticais indicam a existência de diferença estatística significativa pelo teste de Tukey com $5 \%$ de probabilidade de erro.

Esses resultados indicam que o maior peso de folhas foi obtido com os tratamentos NPK e cama de frango, os quais não diferiram estatisticamente entre si. A diferença do peso de folhas com NPK passa a ser observada se comparada com o tratamento à base de pó de rocha e com calcário. Os tratamentos com cama de frango e pó de rocha não apresentaram diferença estatística entre si, e tampouco os tratamentos com pó de rocha e calcário.

Estudos realizados por Knapik et al. (2005) com pó de rocha na cultura de soja, com doses de 0,5 e $2,0 \mathrm{~kg} \mathrm{~m}^{-2}$, resultaram nos maiores pesos de 100 sementes quando aplicado a maior dose do produto, sendo que a adubação convencional com NPK apresentou pior resultado. Outro estudo realizado em Lages - SC, em Cambissolo Húmico, avaliou o efeito de pó de basalto sobre o desenvolvimento e a nutrição do feijão, cuja produtividade média do feijão foi de $704 \mathrm{~kg} \mathrm{ha}^{-1}$. A única diferença encontrada nos tratamentos de pó de basalto versus basalto associado ao esterco foi que o esterco, quando associado ao pó de basalto, promoveu um pequeno incremento na produtividade de grão de feijão. Este pequeno incremento pode ser devido à solubilização da rocha 
promovida pelos microrganismos presentes no material orgânico liberando nutrientes para a cultura (FERREIRA et al., 2009).

Ao conduzirem um estudo com saprólito de basalto, com doses de até $32 \mathrm{Mg} \mathrm{ha}^{-1}$, na cultura do feijão, em um Nitossolo Háplico no município de Urupema - SC, Almeida et al. (2004) não observaram diferença no número de vagens por plantas e do número de grãos por vagem em função dos tratamentos com pó de basalto e esterco bovino e pó de basalto sem esterco bovino, sendo que a produtividade média obtida foi de $1,4 \mathrm{Mg} \mathrm{ha}^{-1}$, decorrente da boa fertilidade do solo no local avaliado.

Em relação ao peso de plantas, verificou-se que os tratamentos com calcário e pó de rocha obtiveram uma média de 200 e $300 \mathrm{~g}$, respectivamente, enquanto os tratamentos com cama de frango e NPK obtiveram, na ordem em que se apresenta, uma média de 390 e 600 g por planta (Figura 4).

Figura 4. Peso de plantas (g) de couve manteiga produzida em sistema de transição orgânica com diferentes fontes de fertilização no Noroeste do Rio Grande do Sul.

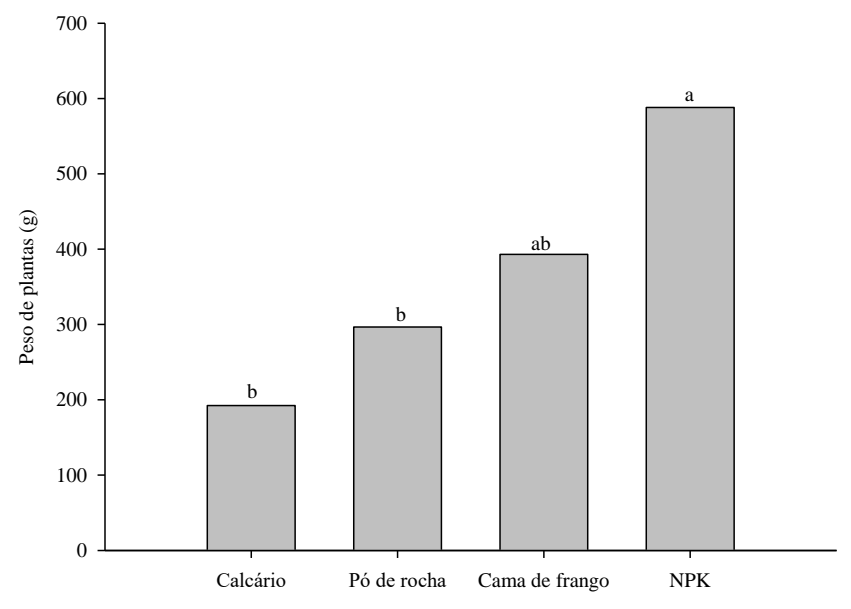

Tratamentos

Letras diferentes entre as barras verticais indicam a existência de diferença estatística significativa pelo teste de Tukey com $5 \%$ de probabilidade de erro.

Como apresentado na Figura 4, os tratamentos com NPK e cama de frango não diferiram estatisticamente entre si, quanto ao peso de plantas. Contudo, os tratamentos com cama de frango, pó de rocha e calcário também não apresentaram diferença estatística significativa entre si para o peso de plantas.

Estes resultados possuem semelhança com experimentos realizados por Pontes et al. (2005) em Juazeiro na Bahia, com coentro, no período de julho a setembro de 2004, utilizando diferentes doses de pó de rocha. Os autores não identificaram diferença significativa na altura das plantas e no rendimento de massa verde, o que foi atribuído, possivelmente, ao pequeno intervalo de tempo entre a aplicação do pó de rocha e a realização do experimento. $\mathrm{O}$ peso do material fresco da parte aérea da planta revelou aumento linear com o incremento de pó de rocha, da ordem de $373 \mathrm{~g} \mathrm{~m}^{-2}$. O rendimento máximo encontrado de massa verde foi de $683 \mathrm{~g}$ $\mathrm{m}^{-2}$.

Em relação à produtividade, verificou-se que os tratamentos com calcário, pó de rocha, cama de frango e NPK obtiveram valores médios, respectivamente, de 7, 11, 15 e 23 $\mathrm{Mg} \mathrm{ha}^{-1}$ (Figura 5).
Figura 5. Produtividade da couve manteiga produzida em sistema de transição orgânica com diferentes fontes de fertilização no Noroeste do Rio Grande do Sul.

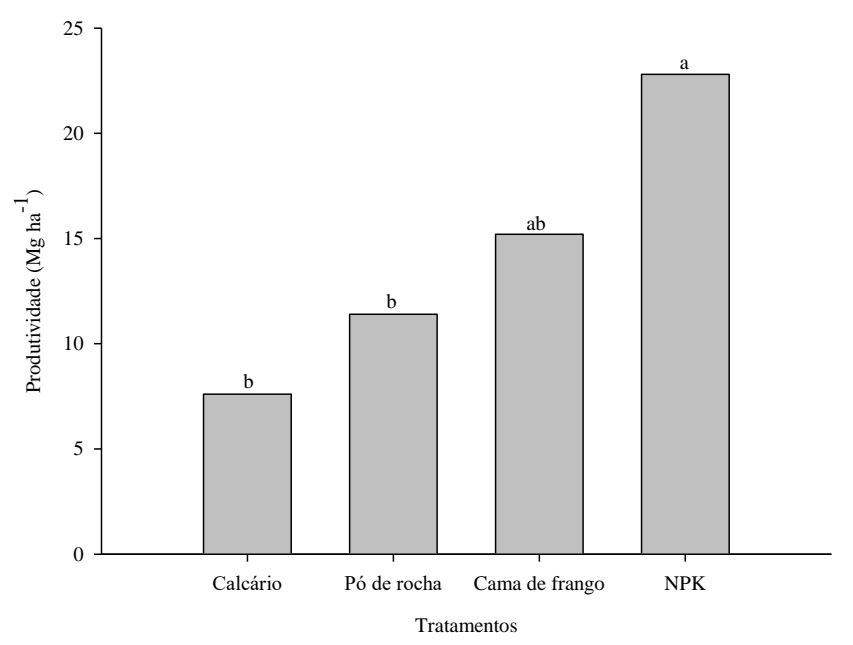

Letras diferentes entre as barras verticais indicam a existência de diferença estatística significativa pelo teste de Tukey com $5 \%$ de probabilidade de erro.

Conforme a Figura 5, apesar da aparente produtividade superior da couve manteiga no tratamento com NPK, esta não diferiu estatisticamente da produtividade obtida com a utilização da cama de frango. Da mesma forma, embora exista a aparente produtividade superior da cama de frango em relação ao pó de rocha e do calcário, não há diferença estatística significativa para os três últimos tratamentos citados.

A produtividade superior do NPK já era esperada, uma vez que os nutrientes são disponibilizados rapidamente no solo, enquanto que a cama de frango e o pó de rocha liberam os nutrientes lentamente. Logo, naturalmente necessitam de maior período de tempo para disponibilização dos nutrientes. Contudo, para Kimoto (1993) a adubação orgânica no cultivo de hortaliças, principalmente nas folhosas, é uma técnica extremamente promissora, pois o adubo orgânico completa as perdas de nutrientes sofridas durante seu cultivo.

Um estudo realizado por Vidigal et al. (2010) destaca a capacidade de produção de cebolas, em Minas Gerais, com adubação orgânica. Os autores relatam a produção de 358,7 $\mathrm{kg} \mathrm{ha}^{-1}$ por dia com um ciclo natural de 168 dias. A produção máxima estimada em $61,5 \mathrm{Mg} \mathrm{ha}^{-1}$ supera em muito a média brasileira para cultivos convencionais que é de $17 \mathrm{Mg} \mathrm{ha}^{-1}$ (VILELA et al., 2005). Um estudo realizado por Pereira et al. (2002) descreve produtividade de $22 \mathrm{Mg} \mathrm{ha}^{-1}$ com fertilização de adubo bovino para a mesma cultivar, porém, em uma região de clima mais frio da região Sul de Minas Gerais, que também superou a média brasileira.

Segundo Peixoto Filho et al. (2013), resultados obtidos em experimentos com alface no Ceará, com tratamentos de cama de frango e fertilizante mineral obtiveram produtividades de 27 e $22 \mathrm{Mg} \mathrm{ha}^{-1}$, respectivamente. Para Souza et al. (2005), o emprego de fertilizantes minerais, especialmente os nitrogenados em alface, é uma prática agrícola que traz resultados satisfatórios em termos da produtividade. Entretanto, deve-se levar em consideração a qualidade final do produto e o melhor custo beneficio, uma vez que o uso desordenado de fertilizantes minerais pode, em alguns casos, prejudicar a saúde do consumidor além de 
onerar o custo de produção, inviabilizando o cultivo de diversas hortaliças.

Dessa forma, os resultados do presente estudo demonstraram ser possível a utilização de formas alternativas de fertilização como o pó de rocha e a cama de frango para obter boas produtividades na cultura de couve manteiga, com a utilização de transição orgânica, especialmente quando da redução de utilização de fertilização química. Nesse contexto a transição orgânica pode ser possível de ser feita desde que sejam respeitadas as características intrínsecas de cada produto a ser utilizado para a fertilização do solo, especialmente no que diz respeito ao tempo de disponibilização e liberação de nutrientes no solo para posterior absorção e utilização pelas plantas.

\section{CONCLUSÕES}

A couve manteiga obteve melhores resultados em relação à altura de plantas, peso de folhas, peso de plantas e produtividade quando cultivada com adubação à base de fertilizante comercial formulado com NPK, em comparação com a couve manteiga cultivada com fertilização à base de pó de rocha.

A fonte de nutrientes cama de frango promoveu resultados similares a fonte NPK em relação à altura de plantas, peso de folhas, peso de plantas e produtividade para a cultura da couve manteiga.

O cultivo da couve manteiga com uso de pó de rocha apresentou resultados similares quando comparado com o uso de cama de frango em relação à altura de plantas, peso de folhas, peso de plantas e produtividade da cultura, apresentando-se como alternativa para fertilização da cultura da couve manteiga em sistema de transição orgânica.

\section{REFERÊNCIAS}

ADELI, A.; SHANKLE, M. W.; TEWOLDE, H. Nutrient Dynamics from Broiler LitterApplied to No-Till Cotton in an Upland Soil. Agronomy Journal, v.100, p.564-570, 2008.

ALMEIDA, D. L.; MAZUR, N. P.; PEREIRA, N. C. Efeitos de composto de resíduos urbanos em cultura do pimentão no município de Teresópolis-RJ. In: Congresso Brasileiro De Olericultura, 22, Vitória. Resumos. Vitória: SOB/SEAG-ES, 1982, p. 322.

ALMEIDA, J. A.; ALMEIDA, K. A.; MAFRA, A. L. Saprólito de basalto com zeólitas como fonte de nutrientes as plantas. In: Reunião de Fertilidade do Solo e Nutrição de Plantas, 26, Lages, 2004. Anais... Lages: Sociedade Brasileira de Ciências do Solo, 1 CD (Resumos/FSNP), 2004.

AMPARO, A. Farinha de rocha e biomassa. Agroecologia Hoje, Botucatu, v.20, n.1, p. 10- 12, 2003.

BATAL, K. M.; GRANBERRY, D. M.; MULLINIX JR, B. G. Nitrogen, magnesium, and boron applications affect cauliflower yield, curd mass, and hollow stem disorder. Hortscience, v.32, p.75-78, 1997.

BLUM, L. E. B.; AMARANTE, C. V. T.; GÜTTLER, G.; MACEDO, A. F.; KOTHE, D.; SIMMLER, A.; PRADO, G.; GUIMARÃES, L. Produção de moranga e pepino em solo com incorporação de cama aviária e casca de pinus. Horticultura Brasileira, Brasília, v.21, n.4, p. 627-631, 2003.

BRANCO, S. M.; MURGEL, P. H.; CAVINATTO, V. M. Compostagem: Solubilização biológica de rocha fosfática na produção de fertilizante organomineral. Engenharia Sanitária e Ambiental, v.6, n.3, p.115-122, 2001.

BRASIL. MINISTÉRIO DA AGRICULTURA, PECUÁRIA E ABASTECIMENTO. Economia e Emprego. Portal Brasil. 2015. Disponível em: <http://www.brasil.gov.br/economia-eemprego/2015/03/em-um-ano-total-de-produtores-organicoscresce-51>. Acesso em: 11 ago. 2017.

CAIRES, E. F.; KUSMAN, M. T.; BARTH, G.; GARBUIO, F. J.; PADILHA, J. M. Alterações químicas do solo e resposta do milho à calagem e aplicação de gesso. Brasileira de Ciência do Solo, v. 28. p.125-136, 2004.

CAMARGO, M. S; MELlO, S. C.; FOLTRAN, D. E; CARMELlO, Q. A. C. Produtividade e podridão parda em couve-flor de inverno influenciadas pelo nitrogênio e boro. Bragantia, v.67, n.2, p.371-375, 2008.

CAPORAL, F. R.; COSTABEBER, J. A. Agroecologia e desenvolvimento rural sustentável: perspectivas para uma nova Extensão Rural. Agroecologia e Desenvolvimento Rural Sustentável, v.1, n.1, p.16-37, 2000.

CELLA, D.; ROSSI, M. C .L. Análise do mercado de fertilizantes no Brasil. Interface Tecnológica; v.7. n.1, p.4150. 2010 .

CQFS-RS/SC. Comissão de Química e Fertilidade do Solo RS/SC. Manual de adubação e calagem para os Estados do Rio Grande do Sul e Santa Catarina. Porto Alegre: SBCSNRS, 2004, 400 p.

FERREIRA, D. F. Sisvar: A computer statistical analysis system. Ciência e Agrotecnologia. Lavras, v.35, n.6, p.10391042, 2011.

FERREIRA, E. R. N. C.; ALMEIDA, J. A.; MAFRA, A. L. Pó de basalto, desenvolvimento e nutrição do feijão comum (Phaseolus vulgaris) e propriedades químicas de um Cambissolo Húmico. Ciências Agroveterinárias. Lages, v.8, n.2, p.111-121, 2009.

FERREIRA, M. M. M.; FERREIRA, G. B.; FONTES, P. C. R.; DANTAS, J. P. Influência das adubações nitrogenada e orgânica no tomateiro sobre os teores de N-NO3- e N-NH4+ no perfil do solo. Brasileira de Engenharia Agrícola Ambiental, v.7, n.2, p.233- 239, 2003.

FONTANÉTTI, A.; CARVALHO, G. J.; GOMES, L. A. A.; ALMEIDA, K.; MORAES, S. R. G.; TEIXEIRA, C. M. Adubação verde na produção orgânica de alface americana e repolho. Horticultura Brasileira, v.24, n.2, p.146-150, 2006.

GLIESSMAN, S. R. Agroecologia: processos ecológicos em agricultura sustentável. Porto Alegre: Editora UFRGS, 2000, $658 \mathrm{p}$. 
HAHN, C. L.; CASARIN, V. A.; SANTOS, A. V. dos; MIRANDA, R. L. de; ORTIZ, L. C. V. Análise de mercado dos produtos da agroindústria familiar: Estudo de caso do perfil do consumidor e do produtor Santo-Angelense - Rio Grande do Sul - Brasil. Espacios, v.38, n.21, 2017, 5 p.

IFA. International Fertilizer Association. 2009. Disponível em:< http://www.fertilizer.org/>. Acesso em: 09 ago. 2017.

KIMOTO, T. Nutrição e Adubação de repolho, couve-flor e brocoli. In: Nutrição e Adubação de Hortaliças. Jaboticabal, 1993. Anais... Jaboticabal: UNESP, p. 149-178. 1993.

KINGERY, W. L.; WOOD, C. W.; DELANEY, D. P.; Williams J. C.; MULLINS G. L. Impact of long-term land application of broiler litter on environmentally related soil properties. Journal Environmental Quality, v.23, p.139-147, 1994.

KNAPIK, B.; KNAPIK, J.G.; SILVA, F.J.P. Utilização de pó de basalto como substituto a adubação química no plantio de soja. In: Congresso Brasileiro de Agroecologia, 3, e Seminário Estadual de Agroecologia, 3, 2005, Florianópolis. Anais... Florianópolis: Epagri/UFSC, 2005.

LEONARDOS, O. H.; FYFE, W. S.; KRONBERG, B. I. Rochagem: O método de aumento da fertilidade em solos lixiviados e arenosos. In: Congresso Brasileiro de Geologia, 29, 1976. Anais... Belo Horizonte, p. 137-145. 1976.

LOPES, P. R; LOPES, K. C. S. A. Sistemas de produção de base ecológica - a busca por um desenvolvimento rural sustentável. Espaço de Diálogo e Desconexão, Araraquara, v.4, n.1, 2011

MAZOYER, M.; ROUDART, L. História das agriculturas no mundo: do neolítico a crise contemporânea. [Tradução de Cláudia F. Falluh Balduino Ferreira]. São Paulo: Editora UNESP; Brasília, DF: NEAD, 2010, p. 568.

McGRATH, S.; MAGUIRE, R. O.; TRACY, B. F.; FIKE, J. H. Improving soil nutrition with poultry litter application in low input forage systems. Agronomy Journal, v.102, n.1, p.48-54, 2009.

MELAMED, R.; GASPAR, J. C. Eficiência de pó de rocha na bio-disponibilidade de potássio em sistemas de produção agrícola sustentáveis. In: XXI Encontro Nacional de Tratamento de Minérios e Metalurgia Extrativa CETEM/COAM, 2005.

NAKAGAWA, J.; BÜLL, L. T.; PROCHNOW, L. I.; VILLAS BOAS, R. L. Efeitos de compostos orgânicos na cultura do alface (Lactuca sativa L.). Série I. Científica, São Paulo, v.20, n.1, p.173-180, 1992.

NILSON, T. The influence of soil type, nitrogen and irrigation on yield, quality ad chemical composition of cauliflower. Swedish Journal of Agricultural Research, Oslo, v.10, p.65-75, 1980.

PEIXOTO FILHO, J. U.; FREIRE, M. B. G. S.; FREIRE, F. J; MIRANDA, M. F. A; PESSOA, L. G. M.; KAMIMURA,
K. Produtividade de alface com doses de esterco de frango, bovino e ovino em cultivos sucessivos. Brasileira de Engenharia Agrícola e Ambiental, v.17, n.4, p. 419-424, 2013.

PEREIRA, A. J.; SOUZA, R. J.; PEREIRA, W. R. Efeito de diferentes doses de esterco de galinha e de curral sobre a produção de cebola. Horticultura Brasileira, Brasília, v.20, suplemento CD-ROM, julho 2002.

PONTES, A. S. C.; ARAÚJO, F. P.; ARAÚJO, J. F.; MOUCO, M. A.; VILLAS BOAS R. L.; FERNANDES, D. M. Emprego do pó de rocha MB-4 sobre a produção de coentro. In: Congresso Brasileiro de Agroecologia, 3; Seminário Estadual de Agroecologia, 3. Florianópolis. Anais... Florianópolis: ABA, 2005.

RAIJ, B. V. Fertilidade do solo e manejo de nutrientes. IPNI, 2011, 420p.

RODRIGUES, P. N. F.; ROLIM, M. M.; NETO, E. B.; PEDROSA, E. M. R.; OLIVEIRA, V. S. Crescimento e composição mineral do milho em função da compactação do solo e da aplicação de composto orgânico. Brasileira de Engenharia Agrícola e Ambiental v.13, n.1, p.94-99, 2009.

SAAB, A. A.; PAULA, R. A. O mercado de fertilizantes no Brasil: diagnósticos e propostas de políticas. Política Agrícola, v.17, n.2, p.5-24, 2008.

SANTOS, H. G. Sistema Brasileiro de Classificação de Solos. 3 ed. rev. ampl. Brasília, DF: Embrapa, 2013, 313p.

SILVA, E. M. N. C. P.; FERREIRA, R. L. F.; ARAÚJO NETO S. E.; TAVELLA, L. B.; SOLINO, A. J. S. Qualidade de alface crespa cultivada em sistema orgânico, convencional e hidropônico. Horticultura Brasileira, v.29, n.2, p.242-245, 2011.

SINGH, Y.; GUPTA, R. K.; THIND, H. S. Poultry litter as a nitrogen and phosphorus source for the rice-wheat cropping system. Biology Fertilizacion Soils, v.45, p.701-710, 2009.

SOUZA, P. A.; NEGREIROS, M. Z.; MENEZES, J. B.; BEZERRA NETO, F.; SOUZA, G. L. F. M.; CARNEIRO, C. R.; QUEIROGA, R. C. F. Características químicas de alface cultivada sob efeito residual da adubação com composto orgânico. Horticultura Brasileira, Brasília, v.23, n.3, p.754$757,2005$.

STEINER, F.; ECHER, M. M.; GUIMARÃES, V. F. Resposta do Almeirão à Aplicação de Três Fontes de Fertilizantes Orgânicos. Brasileira de Agroecologia, v.4, n.2, p. 1905-1908, 2009.

THEODORO, S. M. C. H. A Fertilização da Terra pela Terra: Uma Alternativa de Sustentabilidade para o Pequeno Produtor Rural. 2000. 225f. Tese (Doutorado em Desenvolvimento Sustentável) - Universidade de Brasília, Brasília. 2000.

VALE, F. R. do; GUILHERME, L. R.; GUEDES, G. A.; FURTINI NETO, A.E. Fertilidade do solo: dinâmica e 
disponibilidade dos nutrientes de plantas. Lavras: UFLA/FAEPE, 171p., 1997.

VAN STRAATEN, P. Farming with rocks and minerals: challenges and opportunities. Anais da Academia Brasileira de Ciências, Rio de Janeiro, v.78, n.4, p.731-747, 2006.

VIDIGAL, S. M.; SEDIYAMA, M. A. N.; PEDROSA, M. W.; SANTOS, M. R. Produtividade de cebola em cultivo orgânico utilizando composto à base de dejetos de suínos. Horticultura Brasileira, Brasília, v.28, n.2, p.168-173, 2010.

VILELA, N. J.; MAKISHIMA, N.; OLIVEIRA, V. R.; COSTA, N. D.; MADAIL, J. C. M; CAMARGO FILHO, W.;
BOEING, G.; MELO, P. C. T. Desafios e oportunidades para o agronegócio de cebola no Brasil. Horticultura Brasileira, Brasília, v.23, n.4, p.1029-1033, 2005.

ZHANG, F. S.; YAMASAKI, S.; KIMURA, K. Waste ashes for use in agricultural production: I. Liming effect, contents of plant nutrients and chemical characteristics of some metals.

The Science of the Total Environment, v.284, 1-3, p.215-225, 2002.

ZHANG, H. Animal Manure Can Raise Soil pH. Production technology, Department of Plant and Soil Sciences, v.10, n.7, 1998. 